\title{
Composição Corporal e Exigências Líquidas de Energia e Proteína para Ganho de Peso de Novilhos Santa Gertrudis ${ }^{1}$
}

\author{
Alfredo Acosta Backes ${ }^{2}$, Luis Maria Bonnecarrère Sanchez ${ }^{3}$, Maria Beatriz Fernandes \\ Gonçalves ${ }^{4}$, Cleber Cassol Pires ${ }^{5}$
}

\begin{abstract}
RESUMO - O presente trabalho foi realizado na Universidade Federal de Santa Maria, com o intuito de avaliar a composição corporal e exigências líquidas de energia e proteína de novilhos. Foi conduzido um experimento com uma dieta contendo $70 \%$ de silagem de milho e $30 \%$ de concentrado. Foram utilizados 40 novilhos Santa Gertrudis, com 3,5 anos de idade, sendo quatro deles abatidos no início do experimento e 36 distribuídos ao acaso nos tratamentos e abatidos no final do período experimental. De cada carcaça foi retirada uma secção da $9^{\mathrm{a}}$ à $11^{\mathrm{a}}$ costela e determinada a sua composição física e química, através do que foi estimada a composição corporal. Foram ajustadas as equações lineares entre log do conteúdo de proteína, gordura e energia do corpo vazio e log do peso do corpo vazio. Constatou-se que, ao aumentar o peso do corpo vazio, o conteúdo de proteína desse corpo e do seu ganho de peso diminui, enquanto os de gordura e energia aumentam. Assim, os animais de maior peso corporal vazio apresentam exigências de energia mais elevadas e de proteína inferiores às dos animais de menor peso.
\end{abstract}

Palavras-chave: farinha de carne e osso, silagem, uréia

\section{Body Composition and Liquid Requirements of Energy and Protein for Weight Gain of Santa Gertrudis Steers}

\begin{abstract}
The present work was carried out at Universidade Federal de Santa Maria to evaluate composition of the body and body weight gain. A experiment was conducted with $70 \%$ of corn silage and $30 \%$ of concentrate. Forty 3,5 years old Santa Gertrudis steers were used; four of them were slaughtered at the beginning of the experiment and 36 were randomly assigned to the treatments and slaughtered at the end of the experimental period. From each carcass the $9^{\text {th }}$ to $11^{\text {th }}$ rib section was taken and its physical and chemical composition determined, and from this the body composition was estimated. Linear equations between log of protein, fat and energy content in the empty body and log of empty body weight were fitted. It was observed that increasing empty body weight decreased the content of protein in empty body and in empty body weight gain while it increased fat and energy content. It was also observed that when body weight increased, the requirements of energy increased while those of protein decreased.
\end{abstract}

Key Words: meat and bone meal, silage, urea

\section{Introdução}

A avaliação da composição corporal tem sua importância na determinação das exigências nutricionais dos animais em termos de mantença e produção. Fox \& Black (1984) afirmaram que a predição da composição corporal é necessária para prognosticar o requerimento líquido de nutrientes, o qual pode ser usado como base para predizer o desempenho e o valor das carcaças de bovinos.

Existem fatores que podem influenciar a composição corporal, como peso, taxa de ganho, tamanho corporal, tipo racial, sexo, uso de estimulantes do crescimento, manejo nutricional e efeito da dieta (Fox \& Black, 1984; Teixeira, 1984). Segundo Pires (1991), os fatores estado corporal, sexo, raça e idade exercem grande influência sobre a composição de ganho, assim afetando, também, as exigências de proteína e energia.

A influência da raça e do sexo na composição química de bovinos foi testada no trabalho de Fortin (1980), o qual chegou à conclusão de que o sexo influencia a taxa de agregação de água, proteína e cinzas relativas ao peso corporal, dependendo da

\footnotetext{
${ }^{1}$ Parte da dissertação apresentada pelo primeiro autor para obtenção do grau de Mestre em Zootecnia pela Universidade Federal de Santa Maria (UFSM)

${ }^{2}$ Zootecnista, MSc. e estudante de doutorado da Universidade Federal de Viçosa (UFV) - Alameda Albano Braga, Bloco 01, Ap. 303, Centro - Viçosa, MG, Cep 36570-000. E-mail:abackes@bol.com.br

3 Engenheiro-Agrônomo e professor titular do Departamento de Zootecnia da UFSM.

4 Zootecnista e professora adjunta do Departamento de Zootecnia da UFSM.

${ }^{5}$ Médico Veterinário e professor titular do Departamento de Zootecnia da UFSM.
} 
raça e do nível de consumo de energia. Entretanto, Ferreira et al. (1998) afirmaram que as principais diferenças entre sexos envolvem o tecido adiposo. $\mathrm{O}$ nível de consumo de energia pode modificar a partição no uso da energia para síntese de proteína ou lipídeos ou, em termos de tecidos, no desenvolvimento de músculo e tecido adiposo.

Existem métodos diretos e indiretos para determinar a composição corporal, ressaltando-se que os diretos quantificam o conteúdo de proteína e energia dos tecidos da carcaça. O método ideal seria a análise química completa de todos os tecidos da carcaça, entretanto o uso desse método torna-se inviável devido aos altos custos e ao tempo gasto para sua aplicação e depreciação da carcaça (Alleoni et al., 1997). Em razão desses fatores é que surgiram os métodos indiretos, como a composição física do corte da $9^{\mathrm{a}}$ à $11^{\mathrm{a}}$ costela, onde Alleoni et al. (1997) encontraram alta correlação desse método com a composição química da carcaça.

De todos os métodos que existem, segundo Jesse (1976), a análise química do corpo inteiro do animal ou da carcaça mostra-se o mais preciso.

Existe o método da gravidade específica da carcaça, o qual consiste no resultado da densidade de seus componentes. É um método utilizado por ser rápido e de baixo custo, como verificado nos trabalhos de Teixeira (1984), Peron (1991) e Alleoni et al. (1997).

Significativos coeficientes de correlação, determinados entre conteúdo de energia $(0,84$ a 0,96$)$ e proteína $(0,68$ a 0,91$)$, medidos por três metodologias (gravidade específica da carcaça, gravidade específica da secção da $9^{\mathrm{a}}$ à $11^{\mathrm{a}}$ costela e análise química dos tecidos corporais), indicam que não existem diferenças entre esses métodos (Salvador, 1980).Teixeira (1984) não encontrou diferenças significativas entre dois métodos estudados (gravidade específica da carcaça e gravidade da secção da $9^{a}$ à $11^{\text {a }}$ costela).

Segundo Kelly (1968), quando o teor de gordura da carcaça for menor do que $20 \%$, o método da gravidade específica não é recomendado, por ter baixa correlação com a composição química da carcaça, mas esse mesmo autor afirmou que, quando o teor de gordura for maior do que $40 \%$ da carcaça, a correlação é considerada elevada. Isso evidencia que este método é aplicável apenas para animais que contenham acima de $20 \%$ de gordura na carcaça. Concordando com esse relato, Peron (1991) afirmou

R. Bras. Zootec., v.31, n.6, p.2307-2313, 2002 que o método da gravidade específica é somente utilizado para animais gordos ou em início de engorda.

Existem vários outros métodos indiretos para se estimar a composição da carcaça de bovinos, como: composição física do corte da $9^{\mathrm{a}}$ à $11^{\mathrm{a}}$ costela, composição física do corte da $10^{\mathrm{a}}$ costela ou composição química deste mesmo corte. Ao compararem esses três métodos, Alleoni et al. (1997) encontraram alta correlação entre a composição física das secções da $9^{\mathrm{a}}$ à $11^{\mathrm{a}}$ costela e a composição química da carcaça em relação ao teor de água e ao extrato etéreo, como verificado pelos valores dos coeficientes de determinação e pelos baixos valores do desvio-padrão $\left(\mathrm{R}^{2}=\right.$ 0,86 e 0,$89 ; \mathrm{S}_{\mathrm{yx}}=1,435$; e 1,648 , respectivamente). Com relação à separação física do corte da $10^{\text {a }}$ costela, os componentes físicos deste corte estimaram, com precisão, as frações água e extrato etéreo $\left(\mathrm{R}^{2}=0,76\right.$ e 0,$81 ;$ e $\mathrm{S}_{\mathrm{yx}}=1,876$ e 2,186$)$. Por último, os componentes químico-bromatológicos do corte da $10^{\text {a }}$ costela estimaram, igualmente e com elevada precisão, as mesmas frações $\left(\mathrm{R}^{2}=0,81\right.$ e 0,82 ; e $\mathrm{S}_{\mathrm{yx}}=1,654$ e 2,102$)$. Pode-se concluir, por meio desses dados, que qualquer um desses métodos pode ser utilizado para estimar a composição da carcaça de bovinos.

As diferenças nas exigências de proteína e energia, em termos de ganho, são atribuídas às diferenças na composição do ganho de peso (Garrett, 1959). Em bovinos, após o desaleitamento, nota-se que, à medida que aumenta a idade, a exigência em energia elevase e a de proteína, decresce.

Ao considerar pesos vivos similares, verificou-se que animais precoces apresentam maior exigência de energia e menor de proteína do que animais tardios.

A exigência de energia divide-se em energia líquida disponível para mantença do animal (ELm) e energia líquida disponível para ganho, seja ele em crescimento, seja em engorda (ELg), como verificado nos trabalhos de Lofgreen \& Garrett (1968), Teixeira (1984), Pires (1991), A FRC (1993) e NRC (1996); ou, ainda, em energid líq hida disponível para produção de leite (ELlac) e, tamlém, gestação (ELgest), como verificado p pr Y an Spest (1994).

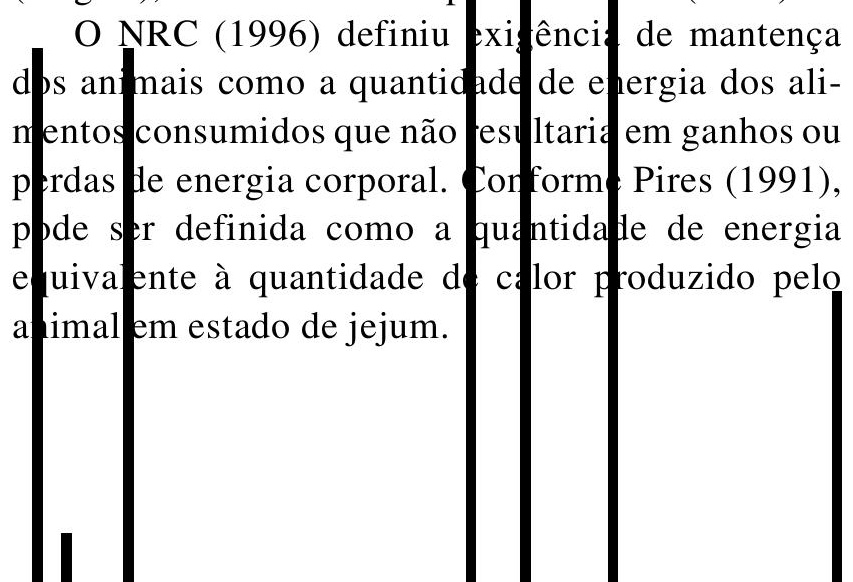


A exigência de energia para mantença é variável, dependendo dos fatores peso, nível de produção, atividade e meio ambiente, genética, composição corporal, condições fisiológica e corporal, aspectos nutricionais, raça e sexo (Solis, 1987; Pires, 1991).

Em bovinos de corte, as exigências de energia líquida de mantença (ELm) são estimadas em $77 \mathrm{kcal} / \mathrm{PV}^{0,75}$ (Lofgreen \& Garrett, 1968). Entretanto, segundo NRC (1984), esse valor refere-se mais a animais estabulados, sem estresse e com atividade normal mínima.

Na tentativa de quantificarem o requerimento de mantença, Rocha et al. (1997), trabalhando com novilhos de origem leiteira de 150 a $300 \mathrm{~kg}$ de peso vivo, encontraram valores de ELm de 68,44 kcal/ $\mathrm{PV}^{0,75}$. Porém, Paulino et al. (1997), trabalhando com zebuínos, obtiveram valores de $60,38 \mathrm{kcal} / \mathrm{PV}^{0,75}$. Através desses dados, pode-se concluir que raças zebuínas são menos exigentes em ELm do que outras raças, o que pode ser devido à menor taxa de metabolismo dos zebuínos.

Lofgreen \& Garrett (1968) definiram a exigência de energia líquida para ganho (ELg) como a energia depositada no ganho. Segundo NRC (1984 e 1996), a exigência de ELg é estimada como a quantidade de energia depositada na forma de proteína e gordura, sendo o valor calórico da gordura de $9,4 \mathrm{kcal} / \mathrm{g}$ e o da proteína, de $5,6 \mathrm{kcal} / \mathrm{g}$.

Trabalhando com exigências de proteína e energia de quatro raças de gado zebuíno (Nelore, Gir, Guzerá e Tabapuã) com peso vivo médio de $360 \mathrm{~kg}$, Paulino et al. (1997) não verificaram diferenças entre raças em exigências líquidas de energia e proteína para ganho de peso. No entanto, sabe-se que animais maduros possuem exigência maior em energia do que animais jovens, independentemente da raça.

Atualmente, as exigências de proteína são calculadas em termos de proteína metabolizável (NRC, 1996). Segundo Valadares Filho (1997), as exigências de proteína dos ruminantes são atendidas pelos aminoácidos absorvidos no intestino delgado, denominadas exigências de proteína metabolizável. Ainda segundo esse mesmo autor, a proteína que chega ao intestino delgado consiste da fração microbiana, fração dietética não-degradada no rúmen e proteína endógena.

Os vários sistemas (NRC, 1984, 1989, 1996 e 2001; AFRC, 1993), nos quais os nutricionistas se baseiam, foram determinados em sistemas geralmente diversos entre eles e que, por conseqüência, con- duzem a valores distintos entre si. Devido a esses fatores, vêm sendo realizados, já a algum tempo, trabalhos científicos sobre análise de exigências de bovinos nas condições brasileiras, visando à obtenção de dados mais precisos.

Dessa maneira, o presente trabalho foi conduzido com a finalidade de determinar a composição corporal e exigências líquidas de energia e proteína para ganho de peso de bovinos da raça Santa Gertrudis.

\section{Material e Métodos}

O experimento foi conduzido nas dependências do Setor de Nutrição Animal do Departamento de Zootecnia da Universidade Federal de Santa Maria, em Santa Maria, RS.

Foram utilizados 40 animais da raça Santa Gertrudis, machos castrados, com idade média de três anos e meio e peso inicial de $390 \mathrm{~kg}$. Adotou-se o método de abate comparativo, em que quatro animais foram abatidos no início do experimento e 36 após o período de 105 dias de confinamento. O confinamento foi dividido em cinco subperíodos de 21 dias, sendo a pesagem dos animais realizada após jejum de 16 horas, no início do experimento e no final de cada subperíodo.

A composição bromatológica dos alimentos volumoso e concentrado é mostrada na Tabela 1 .

Os animais eram arraçoados à vontade, duas vezes ao dia. A proporção volumoso:concentrado foi de 70:30, sendo o concentrado fornecido misturado à silagem, na hora do arraçoamento.

De cada animal abatido foi retirada uma secção da $9^{\text {a }}$ à $11^{\text {a }}$ costela, conforme a metodologia para novilhos descrita por Hankins \& Howe (1946). Essas secções foram separadas em tecidos ósseo, muscular e adiposo, obtendo-se valor percentual de cada tecido em relação à secção inteira. Esses valores percentuais foram utilizados para determinação da composição física da carcaça, por intermédio de equações propostas por Hankins \& Howe (1946), a saber:

$\%$ de músculo na carcaça $=\mathrm{Y}=15,56+0,81(\%$ de músculo na secção)

$\%$ de gordura na carcaça $=\mathrm{Y}=3,06+0,82(\%$ de gordura na secção)

$\%$ de osso na carcaça $=\mathrm{Y}=4,30+0,61(\%$ de osso na secção)

Para realizar as análises bromatológicas dos tecidos, foi necessário o uso do pré-desengorduramento, devido ao fato de que possuíam elevado teor de gordura, 
Tabela 1 - Conteúdo de matéria seca total (MST), matéria orgânica (MO), proteína bruta (PB), fibra bruta $(\mathrm{FB})$, matéria mineral (MM) e extrativos não-nitrogenados (ENN) da silagem e do concentrado

Table 1 - Contents of total dry matter (TDM), organic matter (OM), crude protein (CP), crude fiber (CF), mineral matter (MM) and nitrogen-free extract (NFE) of the silage and concentrate

\begin{tabular}{|c|c|c|c|c|c|c|}
\hline $\begin{array}{l}\text { Alimento } \\
\text { Feed }\end{array}$ & $\begin{array}{c}\text { MST }(\%)+ \\
T D M\end{array}$ & $\begin{array}{c}\mathrm{MO}(\%)^{*} \\
O M\end{array}$ & $\begin{array}{c}\mathrm{PB}(\%)^{*} \\
C P\end{array}$ & $\begin{array}{c}\mathrm{FB}(\%)^{*} \\
C F\end{array}$ & $\begin{array}{c}\mathrm{MM}(\%)^{*} \\
M M\end{array}$ & $\begin{array}{c}\mathrm{ENN}(\%)^{*} \\
N F E\end{array}$ \\
\hline $\begin{array}{l}\text { Silagem de milho } \\
\text { Corn silage }\end{array}$ & 34,94 & 97,02 & 6,44 & 23,8 & 2,97 & 63,43 \\
\hline $\begin{array}{l}\text { Concentrado } \\
\text { Concentrate }\end{array}$ & 95,90 & 95,78 & 16,33 & 1,99 & 4,22 & 73,02 \\
\hline
\end{tabular}

$+=$ matéria natural (as fed).

${ }^{*}$ = matéria seca total (total dry matter).

impossibilitando as análises pelo método de Weende. A pré-desengorduragem foi realizada conforme a metodologia descrita por Kock \& Preston (1979).

Determinaram-se as concentrações de matéria seca total (MST), matéria orgânica (MO), proteína bruta (PB), extrato etéreo (EE) e cinzas (CZ). Os valores obtidos pelas análises de composição químico-bromatológica foram transformados para a carcaça inteira, por intermédio das equações de Hankins $\&$ Howe (1946). Esses valores obtidos de carcaça foram transformados para peso vivo, por meio das equações descritas por Peron (1991), a saber:

Proteína bruta $(\mathrm{PB})=0,33194+0,999075 \mathrm{X}$
Gordura $(\mathrm{GORD})=0,706787+1,053660 \mathrm{X}$
Cinzas $(\mathrm{CZ})=0,799583+0,560468 \mathrm{X}$
Água $=-4,641600+1,103810 \mathrm{X}$
$\mathrm{X}=$ fração determinada quimicamente na carcaça

Os valores de peso vivo (PV) foram transformados para peso do corpo vazio (PCVZ), por intermédio do fator de correção $(1,08)$ definido por Fontes $(1995)$. Foram ajustadas as equações de predição da composição corporal através da regressão do logaritmo do conteúdo corporal de proteína, gordura e energia, em função do logaritmo do peso corporal vazio. Derivando essas equações de predição, obtiveram-se as equações de predição das exigências líquidas de proteína ou energia, para ganho de $1 \mathrm{~kg}$ de PCVZ. A equação utilizada foi do tipo:

$$
\mathrm{Y}^{\prime}=\mathrm{b} \cdot 10^{\mathrm{a}} \cdot \mathrm{x}^{\mathrm{b}-1}
$$

em que $\mathrm{Y}^{\prime}=$ exigência líquida de proteína ou energia; a e $b=$ intercepto e coeficiente de regressão, respectivamente, das equações de predição dos conteúdos corporais de energia ou proteína; e $\mathrm{x}=\mathrm{PCVZ} \mathrm{em} \mathrm{kg}$.

\section{Resultados e Discussão}

O fator de correção utilizado para estimar PV a partir do PCVZ, a fim de possibilitar a conversão de exigências para ganho de PCVZ em exigências para ganho de PV, foi $P V=1,08$. Esse fator foi definido a partir do trabalho de Fontes (1995). Assim, o ganho de $1 \mathrm{~kg}$ de PCVZ corresponde ao ganho de $1,08 \mathrm{~kg}$ de PV.

As equações de regressão do logaritmo do conteúdo corporal de gordura, proteína e energia em função do logaritmo do peso do corpo vazio são apresentadas na Tabela 2. Os valores dos coeficientes de determinação $\left(\mathrm{r}^{2}\right)$ indicaram bom ajustamento das equações aos dados.

Os valores obtidos para o intercepto e coeficiente das equações estão dentro da faixa encontrada na literatura, a exemplo dos trabalhos de Pires (1991) e Lana et al. (1992).

Tabela 2 - Parâmetros das regressões do logaritmo da quantidade de gordura $(\mathrm{kg})$, proteína $(\mathrm{g})$ e energia (kcal) no corpo vazio, em relação ao logaritmo do PCVZ $(\mathrm{kg})$ de novilhos Santa Gertrudis

Table 2 - Parameter of the regression of logarithm of amount of fat ( $\mathrm{kg})$, protein $(\mathrm{g})$ and energy (Kcal) in the empty body, on EBW logarithm of Santa Gertrudis steers

\begin{tabular}{lccc}
\hline & \multicolumn{2}{c}{$\begin{array}{c}\text { Parâmetros } \\
\text { Parameter }\end{array}$} & \\
\cline { 2 - 3 } $\begin{array}{l}\text { Nutrientes } \\
\text { Nutrients }\end{array}$ & $\begin{array}{c}\text { Intercepto } \\
\text { Intercept }\end{array}$ & $\begin{array}{c}\text { Coeficiente } \\
\text { Coefficient }\end{array}$ & $\mathrm{r}^{2}$ \\
\hline $\begin{array}{l}\text { Gordura } \\
\text { Fat }\end{array}$ & $-5,8825$ & 2,9526 & 0,67 \\
$\begin{array}{l}\text { Proteína } \\
\text { Protein }\end{array}$ & $-0,5399$ & 0,9439 & 0,76 \\
$\begin{array}{l}\text { Energia } \\
\text { Energy }\end{array}$ & 0,7232 & 2,0415 & 0,76 \\
\hline
\end{tabular}


Através das equações apresentadas na Tabela 2, foram encontradas as concentrações de gordura $(\mathrm{g})$, proteína (g) e energia (Mcal) por quilograma de PCVZ, para animais de 350 a $550 \mathrm{~kg}$ de PCVZ (Tabela 3).

Verifica-se nessa tabela que, à medida que aumenta o peso corporal, a concentração de gordura e energia se eleva, o que está de acordo com as observações de autores como Peron (1991), Lana et al. (1992) e Fontes (1995) em bovinos.

É sabido que em animais adultos, bem alimentados, a grande responsável pelo aumento do peso vivo é a elevação do conteúdo de gordura corporal. Isso influencia diretamente o aumento das exigências energéticas para ganho. Segundo Paulino (1996), tal fato acontece porque os tecidos adiposos desses animais, em que ocorrerá grande parte do aumento de peso vivo, contêm teores mais elevados de matéria seca que os músculos (cerca de $80 \%$ versus $30 \%$ ). Esse fato parece adequar-se a este experimento, já que os animais foram considerados erados e submetidos a uma boa dieta.
Com relação à proteína, verificou-se que, com o aumento do peso do corpo vazio, a sua concentração diminuiu, e isso está de acordo com dados obtidos por Pires (1991). A concentração de proteína decresce, provavelmente, devido à elevação da concentração de gordura depositada por quilograma de peso vivo.

A maturidade do animal é refletida por aumento na proporção de gordura, acompanhado de decréscimos na proporção de proteína do corpo (Ferreira et al., 1998). Esse fato também acontece com bovinos em período de engorda, em que nos animais magros, à medida que ocorre aumento do seu peso, eleva-se a concentração de gordura e decresce a de proteína. Isso está de acordo com valores encontrados neste trabalho e mostrados na Tabela 3.

Por derivação das equações apresentadas na Tabela 3, foram preditos os ganhos de gordura (g), proteína (g) e energia (Mcal) por quilograma de PCVZ para animais de 350 a $550 \mathrm{~kg}$ de PCVZ (Tabela 4).

Na Tabela 4, notam-se aumento do conteúdo de gordura e energia e diminuição da proteína, à medida

Tabela 3 - Concentração de gordura (g), proteína (g) e energia (Mcal) por 1 kg de peso do corpo vazio (PCVZ) de novilhos Santa Gertrudis

Table 3 - Fat, protein and energy concentration for $1 \mathrm{~kg}$ empty body weight for Santa Gertrudis steers

\begin{tabular}{lccc}
\hline & \multicolumn{3}{c}{$\begin{array}{c}\text { Conteúdo corporal } \\
\text { Body content }\end{array}$} \\
\cline { 2 - 4 } $\begin{array}{l}\text { PCVZ }(\mathrm{kg}) \\
\text { EBW }\end{array}$ & $\begin{array}{c}\text { Gordura }(\mathrm{g} / \mathrm{kg} \text { PCVZ) } \\
\text { Fat }(g / \mathrm{kg} \text { EBW })\end{array}$ & $\begin{array}{c}\text { Proteína }(\mathrm{g} / \mathrm{kg} \text { PCVZ) } \\
\text { Protein }(g / \mathrm{kg} \text { EBW })\end{array}$ & $\begin{array}{c}\text { Energia (Mcal/kg PCVZ) } \\
\text { Energy }(\text { Mcal/kg EBW })\end{array}$ \\
\hline 350 & 122 & 208 & 2,359 \\
400 & 158 & 206 & 2,711 \\
450 & 199 & 205 & 3,065 \\
500 & 244 & 203 & 3,421 \\
550 & 294 & 202 & 3,778 \\
\hline
\end{tabular}

Tabela 4 - Conteúdo de gordura, proteína e energia no ganho de peso corporal vazio de novilhos Santa Gertrudis Table 4 - Fat, protein and energy content in the empty body weight gain of Santa Gertrudis steers

\begin{tabular}{lccc}
\hline & \multicolumn{3}{c}{$\begin{array}{c}\text { Conteúdo corporal } \\
\text { Body content }\end{array}$} \\
\cline { 2 - 4 } PCVZ $(\mathrm{kg})$ & $\begin{array}{c}\text { Gordura }(\mathrm{g} / \mathrm{kg} \text { PCVZ) } \\
\text { Fat }(\mathrm{g} / \mathrm{kg} \text { EBW })\end{array}$ & $\begin{array}{c}\text { Proteína }(\mathrm{g} / \mathrm{kg} \mathrm{PCVZ}) \\
\text { Protein }(\mathrm{g} / \mathrm{kg} \text { EBW })\end{array}$ & $\begin{array}{c}\text { Energia }(\mathrm{Mcal} / \mathrm{kg} \text { PCVZ) } \\
\text { Energy }(\text { Mcal/kg EBW })\end{array}$ \\
\hline 350 & 359 & 196 & 5,454 \\
400 & 466 & 194 & 5,536 \\
450 & 587 & 193 & 6,258 \\
500 & 721 & 192 & 6,984 \\
550 & 868 & 191 & 7,713 \\
\hline
\end{tabular}

\section{R. Bras. Zootec., v.31, n.6, p.2307-2313, 2002}


que eleva o peso corporal do animal, estando de acordo com dados de vários trabalhos (Peron, 1991; Pires, 1991; Fontes, 1995). Os valores dessa tabela corroboram os preconizados pelas normas de alimentação comumente utilizadas (NRC, 1984; AFRC, 1993; NRC, 1996) para bovinos.

A partir dos dados apresentados nas Tabelas 3 e 4, observa-se que, à medida que os animais são mais pesados, a concentração de gordura no corpo vazio e no ganho de peso do corpo vazio eleva-se. Essas modificações na composição do corpo vazio e no ganho de peso têm como consequiência o fato de que as exigências líquidas de energia para ganho de $1 \mathrm{~kg}$ de peso aumentam com a elevação do peso vivo, como mostrado na Tabela 5 .

Derivando as equações da Tabela 2, obtiveram-se as exigências líquidas de proteína e energia por quilograma de ganho de PCVZ, para animais com pesos de 350 a $550 \mathrm{~kg}$ e 324 a $509 \mathrm{~kg}$, respectivamente, de PV e PCVZ (Tabela 5).

Com relação à proteína, verificou-se que as exigências para $1 \mathrm{~kg}$ de ganho de peso diminuem com o aumento do peso vivo. Tais dados estão de acordo com os valores de trabalhos de vários autores (Pires, 1991; Lana et al., 1992; Fontes, 1995; Paulino, 1996; Ferreira et al., 1998).

É de consenso, e adequado a este trabalho, o fato de que, à medida que aumenta o peso vivo do animal, geralmente acima de um ano de idade, ocorrem decréscimo na proporção de proteína e aumento na proporção de gordura no peso de corpo vazio, o que se deve à diminuição do crescimento muscular, juntamente com o aumento do desenvolvimento do tecido adiposo. Como conseqüência, tem-se que a exigência de energia aumenta à medida que eleva o peso vivo e a exigência de proteína decresce, concomitantemente.

Tabela 5 - Exigência líquida de proteína e energia para ganho de $1 \mathrm{~kg}$ de peso corporal vazio de novilhos Santa Gertrudis

Table 5 - Requirements of net protein and energy for empty body weight gain for Santa Gertrudis steers

\begin{tabular}{lccc}
\hline $\mathrm{PV}(\mathrm{kg})$ & $\begin{array}{c}\text { PCVZ }(\mathrm{kg}) \\
E B W\end{array}$ & $\begin{array}{c}\text { Proteína }(\mathrm{g}) \\
\text { Protein }\end{array}$ & $\begin{array}{c}\text { Energia }(\text { Mcal }) \\
\text { Energy }\end{array}$ \\
\hline 35 & 324 & 197 & 4,446 \\
400 & 370 & 194 & 5,077 \\
450 & 417 & 194 & 5,802 \\
500 & 463 & 191 & 6,405 \\
550 & 509 & 190 & 7,074 \\
\hline
\end{tabular}

R. Bras. Zootec., v.31, n.6, p.2307-2313, 2002
Os animais utilizados neste trabalho foram considerados erados, e, portanto, suas exigências energéticas para ganho de $1 \mathrm{~kg}$ tendem a ser maiores do que as de animais jovens. Isso confirma os achados de Ferreira et al. (1998), que, trabalhando com animais Simental x Nelore jovens (17 meses de idade), obtiveram exigências energéticas variando de 2,72 a 3,34 Mcal/kg de PCVZ, respectivamente para 350 a $500 \mathrm{~kg}$ de PV. Esses valores se mostraram inferiores aos encontrados neste trabalho, que foram de 4,45 a 6,40, respectivamente para 350 a $500 \mathrm{~kg}$ de PV.

Os dados deste trabalho, com animais adultos da raça Santa Gertrudis, são de fundamental importância para o conhecimento mais aprofundado das reais exigências nutricionais desse tipo racial nas condições do Brasil. Isso porque as tabelas de exigências nutricionais utilizadas atualmente provêm de outros países, de regiões com meio ambiente e animais com potencial genético adverso ao das nossas condições. Portanto, essas tabelas tendem a não representar fielmente as exigências nutricionais dos animais brasileiros.

\section{Conclusões}

À medida que aumenta o peso corporal diário dos animais, eleva-se também o teor de gordura e diminui o de proteína na composição corporal e no ganho diário do animal. Entretanto, os valores são específicos para animais da raça Santa Gertrudis, os quais possuem poucos dados sobre suas reais exigências nutricionais.

Os animais de maior peso corporal vazio apresentam exigências maiores de energia e menores de proteína que animais de menor peso.

Os valores de exigências de proteína e energia servem, também, como dados para a futura elaboração de uma tabela de exigências nutricionais de ruminantes específica para o Brasil.

\section{Literatura Citada}

AGRICULTURAL AND FOOD RESEARCH COUNCIL AFRC. Energy and protein requirement of ruminants. Wallingford: commonwealth Agricultural Bureaux International, 1993. 159p.

ALLEONI, G.F.; LEME, P.R.; BOIN, C. et al. Métodos indiretos para estimar a composição química da carcaça de novilhos nelore. 1. Gravidade específica. In: REUNIÃO ANUAL DA SOCIEDADE BRASILEIRA DE ZOOTECNIA, 34., 1997, Juiz de Fora. Anais... Juiz de Fora: Sociedade Brasileira de Zootecnia, 1997. p.317-319.

FERREIRA, M.A.; VALADARES FILHO, S.C.; COELHO DA SILVA, J.F. et al. Composição corporal e exigências líquidas 
de proteína e energia para ganho de peso de bovinos F1 Simental x Nelore. Revista Brasileira de Zootecnia, v.28, n.2, p.352-360, 1998.

FONTES, C.A.A. Composição corporal, exigências líquidas de nutrientes para ganho de peso e desempenho produtivo de animais zebuínos e mestiços europeu - zebu. Resultados experimentais. In: SIMPÓSIO INTERNACIONAL SOBRE EXIGÊNCIAS NUTRICIONAIS DE RUMINANTES, 1995, Viçosa, MG. Anais...Viçosa, MG: JARD, 1995. p.419-455.

FORTIN, A. Effect of level of energy intake and influence of breed and Sex on the chemical composition of cattle. Journal of Animal Science, v.51, n.3, p.604-614, 1980.

FOX, D.G.; BLACK, J.R. A system for predicting body composition and performance of growing cattle. Journal of Animal Science, v.58, n.3, p.725-739, 1984.

GARRETT, W.N. The comparative energy requirements of sheep and cattle for maintenance and gain. Journal of Animal Science, v.18, n.3, p.528-547, 1959.

HANKINS, O.G.; HOWE, P.E. Estimation of the composition of beef carcasses and cuts. Washington: USDA, 1946. (Technical Bulletin - USDA, 926).

JESSE, G.W. Effects of rations energy and slaughte weight on composition of empty body ad carcasses gain of beef cattle. Journal of Animal Science, v.43, n.2, p.418-425, 1976.

KELLY, R.F. Estimates of carcasses composition of beef cattle fed at different planes of nutrition. Journal of Animal Science, v.27, n.3, p.620-627, 1968.

KOCK, S.W.; PRESTON, R.L. Estimation of bovine carcass composition by the urea dilution technique. Journal of Animal Science, v.48, n.2, p.319-327, 1979.

LANA, R.P.; FONTES, C.A.A.; PERON, A.J. et al. Composição corporal e do ganho de peso e exigências de energia, proteína e macroelementos minerais ( $\mathrm{Ca}, \mathrm{P}, \mathrm{Mg}, \mathrm{Na}$ e $\mathrm{K}$ ), de novilhos de cinco grupos raciais. 3. Conteúdo corporal e do ganho de peso e exigências de macroelementos minerais. Revista Brasileira de Zootecnia, v.21, n.3, p.538-544, 1992.

LOFGREEN, G.P.; GARRETT, W.N. A system for expressing net energy requirements and feed values for growing and finishing beef cattle. Journal of Animal Science, v. 27, n.3, p.793-806, 1968.

NATIONAL RESEARCH COUNCIL - NRC. Necessidades nutritivas del ganado vacuno. 3.ed. Buenos Aires: Hemisfério Sur., 1984. 104p.

NATIONAL RESEARCH COUNCIL - NRC. Nutrient requirements of beef cattle. 7.ed. Washington, D.C.: [s.n.], 1996. 243p.

NATIONAL RESEARCH COUNCIL - NRC. Nutrient requirements of dairy cattle. 6.ed. Washington, D.C.: [s.n.], 1989. 158p.

NATIONAL RESEARCH COUNCIL - NRC. Nutrient requirements of dairy cattle. 7.ed. Washington, D.C.: [s.n.], 2001. 381p.

PAULINO, M.F. Composição corporal e exigências de ener- gia, proteína e macroelementos minerais $(\mathrm{Ca}, \mathrm{P}, \mathrm{Mg}, \mathrm{Na}$ e K) de bovinos de quatro raças zebuínas em confinamento. Viçosa, MG: Universidade Federal de Viçosa, 1996. 80p. Tese (Doutorado em Zootecnia) - Universidade Federal de Viçosa, 1996.

PAULINO, M.F.; FONTES, C.A.A.; JORGE, A.M. Exigências de energia e proteína para ganho de peso de bovinos não castrados de quatro raças zebuínas em confinamento. In: REUNIÃO ANUAL DA SOCIEDADE BRASILEIRA DE ZOOTECNIA, 34, 1997, Juiz de Fora. Anais... Juiz de Fora: Sociedade Brasileira de Zootecnia, 1997. p.16-18.

PERON, A.J. Características e composição física química, corporal e da carcaça de bovinos de cinco grupos genéticos, submetidos a alimentação restrita e ad libitum. Viçosa, MG: Universidade Federal de Viçosa, 1991. 138p. Dissertação (Mestrado em Zootecnia) - Universidade Federal de Viçosa, 1991.

PIRES, C.C. Exigências de proteína, energia e macroelementos minerais (Ca, P, Mg, Na e K). Viçosa, MG: Universidade Federal de Viçosa, 1991. 125p. Tese (Doutorado em Zootecnia) - Universidade Federal de Viçosa, 1991.

ROCHA, E.O.; FONTES, C.A.A.; CASTRO, A.C.G. Exigências nutricionais e características produtivas de novilhas de origem leiteira. 2. Exigências de energia e proteína para mantença do ganho de peso. In: REUNIÃO ANUAL DA SOCIEDADE BRASILEIRA DE ZOOTECNIA, 34., 1997, Juiz de Fora. Anais... Juiz de Fora: Sociedade Brasileira de Zootecnia, 1997. p.6-8.

SALVADOR, M. Exigências de energia e proteína para engorda de novilhos azebuados. Viçosa, MG: Universidade Federal de Viçosa, 1980. 70p. Dissertação (Mestrado em Zootecnia) - Universidade Federal de Viçosa, 1980.

SOLIS, J.C. Maintenance requirements and energetic efficiency of cows of different breed types. Journal of Animal Science, v.58, n.3, p.764-773, 1987.

TEIXEIRA, J.C. Exigências de energia e proteína, composição e área corporal e principais cortes da carcaça em seis grupos genéticos de bovídeos. Viçosa, MG: Universidade Federal de Viçosa, 1984. 110p. Tese (Doutorado em Zootecnia) - Universidade Federal de Viçosa, 1984.

VALADARES FILHO, S.C. Digestão pós-ruminal de proteínas e exigências de aminoácidos para ruminantes. In: SIMPÓSIO INTERNACIONAL DE DIGESTIBILIDADE EM RUMINANTES, 1997, Lavras. Anais... Lavras: FAEPE, 1997. p.87-113.

Van SOEST, P.J. Nutritional ecology of the ruminant. 2.ed. Ithaca: Cornell Universiy Press, 1994. 476p.

Recebido em: 15/01/02

Aceito em: 14/08/02 